\title{
Essential to increase the use of generics in Europe to maintain comprehensive health care?
}

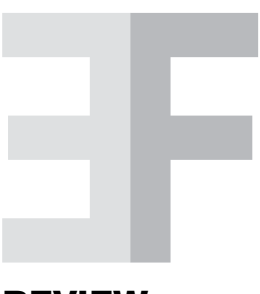

REVIEW

\author{
Brian Godman ${ }^{1,2,3}$, Marion Bennie ${ }^{4,5}$, Christoph Baumgärtel ${ }^{6}$, Ljiljana Sović-Brkičić ${ }^{7}$, Thomas Burkhardt ${ }^{8}$, \\ Jurij Fürst ${ }^{9}$, Kristina Garuoliene ${ }^{10}$, Miguel Gomes ${ }^{11}$, Vanda Markovic-Pekovic ${ }^{12,13}$, Andrew Martin ${ }^{14}$, \\ Catherine Sermet ${ }^{15}$, Peter Skiold ${ }^{16}$, Menno van Woerkom ${ }^{17}$, Luka Voncina ${ }^{18}$, Lars L. Gustafsson ${ }^{3}$ \\ Institute for Pharmacological Research 'Mario Negri', Milan, Italy; godman@marionegri.it \\ 2 Prescribing Research Group, University of Liverpool Management School, Chatham Street, Liverpool, UK L69 7ZH \\ 3 Department of Laboratory Medicine, Division of Clinical Pharmacology, Karolinska Institutet, Karolinska University Hospital \\ Huddinge, Stockholm, Sweden; Brian.Godman@ki.se \\ 4 Strathclyde Institute for Pharmacy and Biomedical Sciences, University of Strathclyde, Glasgow, United Kingdom \\ 5 Information Services Division, NHS National Services Scotland, Edinburgh, United Kingdom, EH12 9EB; marion.bennie@strath.ac.uk \\ - Austrian Medicines and Medical Devices Agency, Traisengasse 5, Wien, Austria; christoph.baumgaertel@ages.at \\ Department of Drugs and Medical Products, Croatian Institute for Health Insurance, Zagreb, Croatia; Ljiljana.Sovic-Brkicic@hzzo.hr \\ 8 Hauptverband der Österreichischen Sozialversicherungsträger, Kundmanngasse 21, Wien, Austria \\ 9 Health Insurance Institute, Ljubljana, Slovenia; jurij.furst@zzzs.si \\ ${ }^{10}$ Medicines Reimbursement Department, National Health Insurance Fund, Vilnius, Lithuania \\ 11 INFARMED, Parque da Saúde de Lisboa, Lisboa Portugal; Miguel.Gomes@infarmed.pt \\ ${ }^{12}$ Faculty of Medicine, University of Banja Luka, Banja Luka, Republic Srpska, Bosnia and Herzegovina \\ ${ }^{13}$ Ministry of Health and Social Welfare, Banja Luka, Republic Srpska, Bosnia and Herzegovina \\ ${ }^{14} \mathrm{NHS}$ Bury, Bury, UK; andrew.martin@bury.nhs.uk. \\ ${ }^{15}$ IRDES, 10, rue Vauvenargues, 75018, Paris, France; sermet@irdes.fr \\ ${ }^{16}$ Dental and Pharmaceuticals Benefits Agency (TLV), Stockholm, Sweden; peter.skiold@tlv.se \\ ${ }^{17}$ Dutch Institute for Rational Use of Medicines, 3527 Utrecht, Netherlands; m.woerkom@medicijngebruik.nl \\ ${ }^{18}$ Ministry of Health, Republic of Croatia, Zagreb, Croatia; luka.voncina@miz.hr
}

\begin{abstract}
INTRODUCTION: Reforms have been introduced across Europe to increase prescribing efficiency with existing drugs. These include measures to lower prices of generics as well as increase their prescribing versus originators and patented products in a class or related class. This is essential to maintain comprehensive health care in Europe given continued pressures. The alternative is insufficient funds for new innovative drugs and increasing drug volumes with ageing populations. OBJECTIVE: To review the influence of measures and initiatives to increase the prescribing and dispensing of generics at low prices on ambulatory care prescribing efficiency. In view of this, provide guidance as authorities strive to introduce further reforms to meet their goals. METHODOLOGY: A narrative review of published papers combined with case histories. RESULTS: The different supply- and demand-side measures have reduced generic prices to as low as $2 \%$ to $3 \%$ of pre-patent loss prices in some cases as well as appreciably enhanced their utilisation. As a result, prescribing efficiency has increased without compromising care. In some cases, the reforms have led to expenditure actually falling despite appreciably increased volumes. CONCLUSIONS: Increasing use of generics at low prices will help maintain the European ideals of comprehensive and equitable health care. However, countries will continually need to learn from each other.
\end{abstract}

\section{Keywords}

Demand-Side Measures; Europe; Generics; Pharmaceuticals; Pricing; Supply-Side Measures

\section{INTRODUCTION}

Pharmaceutical expenditure has been rising during the past decade with growth rates up to $13 \%$ per annum, which is typically greater than other components of health care [1-13]. Overall, expenditure on pharmaceuticals has risen by more than $50 \%$ in real terms between 2000 and 2009 among OECD countries [12], resulting in pharmaceutical expenditure as high as $60 \%$ of total health care expenditure in some countries $[14,15]$. In Europe, pharmaceutical expenditure averaged $17.5 \%$ of
Corresponding author

Dr. Bian Godman

Brian.Godman@ki.se

Disclosure

The majority of the authors are employed directly by health authorities or health insurance agencies or are advisers to these organisations. No author has any other relevant affiliation or financial involvement with any organisation or entity with a financial interest in or financial conflict with the subject matter or materials discussed in the manuscript. No writing assistance was utilised in the production of this manuscript. 
total health care expenditure in 2009 , ranging from $7.3 \%$ in Denmark to $32.6 \%$ in Hungary $[12,16,17]$. This is set to continue unless addressed, driven by well recognised factors including strict clinical targets, changing demographics with ageing populations, the continued launch of new premium priced drugs and rising patient expectations $[1-5,7,8,12,15,18]$. New cancer drugs are a particular concern with cancer rates rising, cancer now seen as a chronic disease through advances in treatments, the acquisition costs of cancer drugs typically higher than average drug costs, and new cancer drugs currently a significant proportion of new drugs in development, estimated currently at over 350 , with some new cancer drugs being launched at approximately US $\$ 10,000$ per month [18-30]. As a result, health authorities and health insurance companies across Europe have instigated multiple reforms to slow down this growth in expenditure, or even reverse it, to maintain the European ideals of equitable and comprehensive health care [1-11,15,3154]. The alternative is no or reduced funding for new innovative premium priced drugs as authorities struggle to stay within agreed budgets during this current financial situation, and greater acknowledgement of opportunity costs, which is already happening $[6,9,12,35,55-57]$. This is not in the best interest of all major stakeholder groups. The reforms and initiatives include measures to enhance prescribing efficiency for both new and existing drugs. Initiatives for new drugs include the development of new models to help optimise their use, which centre on three pillars. The three pillars include horizon scanning and budgeting pre-launch, critical drug evaluation peri-launch including possible risk-sharing arrangements, as well as monitoring of prescribing against agreed guidance post launch and, where possible, patient registries to assess the effectiveness and safety of new drugs in routine care [18,19,58-65]. Considerable effort has been directed towards enhancing the prescribing efficiency of existing drugs, based on generics [1$11,15,33,40,66]$. This especially with global sales of pharmaceutical products likely to lose their patents between 2008 and 2013 estimated at US\$50-100bn (€35-70), and US\$255bn between 2011 and 2016, out of total pharmaceutical sales of US $\$ 820 \mathrm{bn}$ in 2009 (€579bn) including US\$700bn from OECD countries [6-10,15,67-69], and generic substitution estimated to reduce costs to patients by an average of $60 \%$ in middle income countries alone [17,70]. As a result, present considerable opportunities for $\mathrm{Eu}-$ ropean countries to learn from each other to further enhance their prescribing efficiency as they struggle to meet patient demands, especially with pharmaceutical budgets now being cut in some countries $[12,35,36]$. This has been recognised by High Level Pharmaceutical Forums and the European Commission, both emphasising the need for increased use of generics, with competition enhancing the potential for lower prices for generics in order that more patients can be treated within target budgets [11,40,71-73]. In addition, potentially liberating monies to fund new innovative drugs [6-11,40,71,72]. However, this philosophy has not always been followed by individual companies, some of whom try and manipulate the market to maintain sales of their originator products for as long as possible $[6,52,54,74]$. The World Health Organization (WHO) also endorses the use of generics when discussing the rational use of medicines as well as potential strategies to release resources to help maximise health gain with available budgets $[17,40,63,70,75]$. This is different to the instigation of outpatient tendering for pharmaceuticals to help reduce costs, which may also include generics [13]. The various initiatives can be divided into supply-side reforms and demand-side reforms. Supply-side reforms include measures to lower the price of generics, accelerate their marketing authorisation, reference pricing for the molecule (Anatomical Therapeutic Classification - ATC - Level 5 [76]), the class (ATC Level 4) or the therapeutic area (ATC Level 3), as well as compulsory price cuts when target budgets are being exceeded $[1-8,10,11,14,15,31-35,37,38,40-42,44$, $52,77,78]$.

Demand-side measures include those to enhance the prescribing, requesting and dispensing of generics versus originators, as well as enhance the prescribing of generics in a class or related class versus still patented products where all drugs in the class are seen as essentially similar for all or nearly all patients [1-11,15,31-38,41-53,63]. This includes the promotion of lower cost medicines where generics are available in a class, e.g. Belgium and Germany $[11,31,40,53,66]$.

Patient care should not be compromised with increased use of generics versus originators apart from a small number of well known examples [3,4,6-8,10,15,37,38,41,79,80].

These include cyclosporine, lithium, certain long acting calcium channel blockers as well as some morphine preparations $[31,41,79,80]$. This is because in Europe generic medicines have to demonstrate the same qualitative and quantitative composition and the same pharmaceutical formulation and bioavailability as the originator medicine to receive market 
authorisation $[6,8,10,15,40,81]$. The predefined acceptance limits for bioequivalence for different batches of generics ensure that plasma concentrations vary only by $3-4 \%$ on average from those of the originator, i.e. the same for different batches of the originator, which is seen as clinically irrelevant in the vast majority of situations $[81,82]$. As a result, health authority and health insurance company personnel typically assume that if two medicines have the same bioavailability they should have a similar therapeutic effect. This is typically the case even when the generic is a different salt to the originator with initially different indications when first approved by the European Medicines Agency (EMA). This happened with generic clopidogrel despite the efforts of the originator company to persuade physicians to continue prescribing Plavix ${ }^{\circledR}[52,82,83]$. This belief is strengthened by the continual monitoring of the quality of generics by EMA and regulatory authorities in member states, leading for instance to the withdrawal of some versions of generic clopidogrel when there were concerns with the manufacturing process $[52,82]$. This is illustrated by two recent literature reviews comparing the outcomes between generic and originator drugs for the treatment of different disease areas $[84,85]$, which again failed to show any superiority of the originator [82]. The first review, which was concerned with medicines for the management of epilepsy, found no evidence of an association between loss of seizure control and treatment with a generic drug versus the originator with at least three anti-epileptic drugs, one of which was phenytoin [84]. Subsequent studies have shown that patients with epilepsy can be successfully switched between different generic versions of the same molecule [86]. The second review concerned various treatments for cardiovascular disease. This again failed to demonstrate any superiority in outcomes for originators compared with generic drugs of the same molecule [85]. This included drugs with a narrow therapeutic index such as propafenone and warfarin [85]. Recent published studies have also shown that generic and originator atorvastatin were equally effective in correcting the lipid profile and reducing the coronary risk in patients with hyperlipidemia and increased risk, and both were equally well tolerated [87].

Patient care should also not be compromised with increased use of generics versus existing patented products in high volume classes such as the proton pump inhibitors (PPIs), HMG CoA reductase inhibitors (statins) and renin-angiotensin system inhibitor drugs
(Angiotensin Converting Enzyme Inhibitors - ACEIs - and Angiotensin Receptor Blockers - ARBs). This can be seen by health authorities and health insurance companies believing:

- PPIs [1,2,4-10,15,31,37,38,41-43,46,49, 53,63]: all PPIs seen to have similar effectiveness.

- Statins [1,2,4-10,37,38,41-43,45-47,49, 63,88-93]: no appreciable difference between generic statins such as simvastatin and patented statins, atorvastatin and rosuvastatin, in the vast majority of patients. This is endorsed by IDEAL study, which failed to show a significant reduction in coronary vascular events for patients prescribed high dose atorvastatin $(80 \mathrm{mg} /$ day) versus low dose simvastatin (20mg/ day), and a recent meta-analysis demonstrating that at comparable doses all statins appear therapeutically equivalent in reducing LDL-C levels. A recent ecological study also showed that outcomes in terms of the subsequent impact of drug treatment on lipid levels were similar whether patients were prescribed formulary drugs (including generic simvastatin) versus non-formulary drugs including patented statins. Published studies have also shown that patients can be successfully switched between statins without compromising care, and physicians in the UK extensively use generic simvastatin to achieve agreed target lipid levels in the Quality and Outcomes Framework to help maximise their income.

- ACEIs/ARBs [5,9,33,42,44,48,49,90,94100]: no differences in effectiveness between ACEIs and ARBs, with prospective clinical studies shown that a dry cough only occurring in approximately $10 \%$ of patients prescribed ACEIs and only 2\% to $3 \%$ of patients in ACEI clinical trials discontinued their treatment due to a dry cough. Patented ARBs can be prescribed second line where there are concerns with tolerance or side-effects with ACEIs, especially as a recent ecological study showed outcomes, in terms of the subsequent impact of drug treatment on blood pressure, were similar whether patients were prescribed formulary drugs (including generic ACEIs) versus non-formulary drugs (including patented ARBs). The first generic ARB, losartan, has now been launched across Europe with other generic ARBs recently launched or about to be launched further enhancing ARB prescribing efficiency. This especially with meta-analyses and patient registry studies showing no differences in effectiveness 
between ARBs for the management of hypertension or heart failure when used at optimal doses, although typically higher doses are needed for heart failure. In addition, published studies have shown that patients can be successfully switched between ARBs.

\section{OBJECTIVE}

The objective of this paper is to review the influence of the plethora of measures and initiatives introduced across Europe in recent years to enhance the prescribing and dispensing of generics at low prices. In view of this, improve prescribing efficiency in ambulatory care especially for drugs in high volume classes. In this case, prescribing efficiency is defined as drug volumes increasing at a faster rate than expenditure where the drugs in each class or related class are seen as essentially similar in all or nearly all patients. As a result, provide guidance to health authorities and health insurance companies across Europe as they strive to instigate additional measures to further enhance their prescribing efficiency to meet their goals.

\section{METHODOLOGY}

This is a narrative review of papers on the influence of generics on increasing prescribing efficiency. The papers will principally be taken from the extensive number of publications that the co-authors have either been involved with or are known to them. Case histories will also be included to further illustrate the influence of multiple measures. These will again be based on publications or internal documents known to the co-authors. We did not undertake a systematic review of published papers concerning generics, as this has already been performed by the coauthors and others. In addition, we did not critique the quality of the papers using established methodologies as a number of the papers quoted are reviews rather than primary research. However, we believe our approach is valid given the extensive experience and publications of the co-authors from across Europe with instigating measures and initiatives to lower the prices of generics as well as increase their utilisation versus originators and patented products in a class.

\section{RESULTS}

These will be divided into four components. Firstly, a review of different approaches to the pricing of generics from across Europe combined with selected case histories which illustrate potential ways to achieve low price. Secondly, a review of potential methods to enhance the prescribing and dispensing of generics versus originators. Thirdly, a review of potential methods to enhance the utilisation of generics versus patented products in a class or related classes. Fourth, combining supply- and demand-side measures in selected case histories to give future guidance.

\section{Measures to obtain low prices for generics}

European countries typically have different approaches to the pricing of generics, with member States free to develop their own national policies for the pricing and reimbursement of drugs [11]. However, they can be categorised into $[1-4,6,8,10,36,37,40-$ 44,46,47,76, 101-103]:

- Prescriptive pricing policies (price regulated systems): this includes mandated prices for generics such as the "stepped price" model in Norway with a maximum $85 \%$ reduction versus pre-patent loss prices for high volume generics, and France where initially generics have to be priced at least $55 \%$ below pre-patent loss prices to be reimbursed. However, there are concerns depending on the level of the prescriptive price reductions that generic manufacturers will subsequently undertake appreciable discounting in the distribution chain to enhance the possibility of their generic being preferentially dispensed. As a result, reducing competition whilst also reducing potential savings to health care systems, especially where the price of some generics vary up to 36 fold across countries depending on the molecule and country, potentially making some policies unsustainable in the long term.

- Market forces: where there is free pricing. This is typically combined with measures to enhance the prescribing of generics versus originators including high INN (International Non-proprietary Name) prescribing (voluntary or compulsory), compulsory substitution or financial incentives including additional co-payments for a more expensive product than the referenced price molecule (ATC Level 5).

- Mixed approach (combination of the two): this combines both approaches, e.g. in Finland the first generic must be priced at least $40 \%$ below pre-patent loss originator prices to be reimbursed, with subsequent generics priced lower to be reimbursed along with market force measures encouraging the prescribing and dispensing of the least costly generic. In Austria, the first generic must be priced 
$48 \%$ below pre-patent loss originator prices to be reimbursed, the second generic $15 \%$ below this, and the third generic $10 \%$ below the second. This results in $60 \%$ below pre-patent loss prices for reimbursement (also setting the reimbursed price also for the originator). Successive generics must be priced at least 10 cents per pack lower than the previous generic to be reimbursed, with mar-

\section{Country}

\section{Measures and their outcomes}

France (prescriptive pricing) $[2,6,8,10,15]$

Croatia (mixed approach) [9,32-34]

Lithuania (mixed approach) $[6,9,35,36]$

Netherlands (mixed approach with increasingly market forces) [104-108]

Republic Srpska (mixed approach) [42]
- In France the first generics have to be priced at least $55 \%$ below pre-patent loss prices to be reimbursed. Prices reduce by a further $7 \%$ after 18 months

- This coupled with multiple policies to enhance the prescribing and dispensing of generics (see text) led to annual savings estimated at €1bn in 2007, €0.905bn in 2008 and €1.01bn in 2009

- First generic must be priced no higher than $70 \%$ of the average prices in three countries in order (Italy, France and Slovenia); alternatively Spain or Czech Republic

- Subsequent generics must be priced up to $90 \%$ of the last bioequivalent product to be reimbursed with market forces including higher co-payments for more expensive generics helping to lower prices

- Alongside this instigation of a new reference pricing system for existing drugs (ATC Levels 3 and 4) based on the lowest price of products with a market share of at least $5 \%$ by expenditure during the preceding 12 months, with patients paying the price difference for a more expensive product. Manufacturers can opt to lower prices of their other products if problematic, e.g. limited opportunities for substitution such as antiepileptic drugs

These measures, combined with reforms regarding the pricing of new products including price: volume agreements, resulted in 47 new products being added to the health insurance reimbursement list between 2009 and 2010. They also:

- reduced health insurance expenditure by $€ 0.2 b n$ during the first 6 months of 2010 versus 2009

- helped stabilise expenditure on drugs for Parkinson's Disease between 2005 and 2010 despite appreciable increases in volumes which included patented add-on therapies such as ropinirole and pramipexole

- The first generic launched must be priced no higher than $30 \%$ below the originator, the second generic at least 10\% lower than the first generic on a pack basis and the third generic 10\% lower than the second to be reimbursed. Once there are more than 3 manufacturers for the molecule, a maximum list price for the originator at $60 \%$ above the cheapest generic (2010), dropping to 30\% in 2011

- New generics are automatically included in existing reference price groups for the molecule grouped by INN, method of administration, indication and length of action, with the cheapest molecule establishing the reference price. Patients have to cover the price difference for a more expensive products themselves

- Benchmarking prices of generics against other European countries including Bulgaria and Romania In addition:

- All reimbursed prescriptions should be written by INN name except biological products, unless the physician receives prior approval from the Hospital or Polyclinic Therapeutic Committee

- Pharmacists must provide pricing information to patients on a computer screen, and dispense the cheapest generic, else an initial fine of Ltk100 (€30) with further abuse resulting in the pharmacy no longer able to dispense prescriptions on behalf of the Lithuanian Health Insurance Agency

These measures, combined with regulations for new medicines including price: volume agreements, resulted in a target reduction of $6 \%$ in pharmaceutical expenditure in 2010 vs. 2009, with the number of prescriptions fully reimbursed increasing by $9 \%$.

Individually:

- generic omeprazole in 2009 was 56\% below pre-patent loss prices in 2000 (Expenditure/DDD) mirroring other European countries

- generic simvastatin in 2009 was 83\% below pre-patent loss prices in 2000 (Expenditure/DDD) with prices still falling

- generic atorvastatin in 2009 was $87 \%$ below pre-patent loss prices in 2001

- In 2004, a covenant was instigated whereby generics should be priced no higher than $40 \%$ below the originator for reimbursement, with additional agreements after this to further lower prices

- Preference pricing policy instigated in 2008 whereby only the cheapest generics would be reimbursed, with patients covering the costs for a non-preferred drug. Tenders were conducted for high volume generics to achieve low prices. This resulted in:

- appreciable price reductions of between $76 \%$ to $93 \%$ for the 10 largest generics by volume, leading to estimated savings of €348mn/year

- the scheme being extended in 2009 as more generics became available resulting in pharmaceutical expenditure stabilizing in the Netherlands in recent years

- both generic omeprazole and generic simvastatin in 2010 at just $2 \%$ of originator pre-patent loss prices (expenditure/DDD)

However, there are concerns regarding the sustainability of pharmacies and the generic industry in the Netherlands as a result of the preference pricing policy

- In 2006, the reference price for the molecule (ATC Level 5) became the current median price among those molecules currently reimbursed and on the market in the Republic Srpska

- From the beginning of May 2008, the reference price became the lowest priced molecule (ATC Level 5), with patients required to cover the difference themselves for a more expensive drug. Market forces, including financial and other measures to increase INN prescribing as well as encourage substitution, are expected to further drive down generic prices as different generics receive market authorisation

- Reimbursed expenditure/DDD for PPIs, statins and ACEIs/ARBs decreased by up to $82 \%$ in 2010 versus 2004 prices, with reimbursed expenditure/DDD for generic omeprazole, simvastatin and ACEls some of the lowest in Europe 
$>$ continues

Sweden (market forces)

$[3,4,6,8,15$, 109,110

UK (market forces)

$[6,8,10,15,31$, $33,37,38]$

Compulsory generic substitution was introduced in 2002 unless:

- the prescriber indicates that the drug should not be substituted on medical grounds

- substitution may be restricted for reasons such as differences in taste for oral solutions or divided tablets - the patient is willing to pay the price difference for a more expensive branded generic originator

In practice, substitution almost always happened helped by an increasing focus on drug costs within the regions (counties in Sweden) following devolution of drug budgets and physician acceptance of this reform.

As a result:

- generic prices fell on average of $40 \%$ by the end of 2005 compared with 2002 , with prices for high-volume drugs falling further - reaching 4 to $13 \%$ of originator pre-patent loss prices by 2009 , helped a comprehensive technical support system enabling pharmacies to continually stock the cheapest product with prices reviewed at least twice a month by the reimbursement agency (TLV), facilitated by one national pharmacy chain - Apoteket $A B$ - owned by and reporting directly to the government (currently TLV reviews the prices of generics once a month whilst the availability of generics is typically undertaken daily). The TLV estimated overall savings of $€ 700$ million (>6.97 billion SEK) from 2002 to the end of 2005. Expected savings from the tendering process are $8 \mathrm{bn}$ SEK/year from 2011 onwards

- the TLV estimated overall savings of $€ 700$ million (>6.97 billion SEK) from 2002 to the end of 2005

However, there were occasions when prices of some generics rose from one month to the next. In addition, there is currently competition among community pharmacists in Sweden. Consequently since 2009 :

- all pharmacies are obligated to offer patients the cheapest molecule currently on the market (ATC Level 5) when there are substitutable generic medicines available. In return, they received €1/package extra when dispensing drugs subject to generic competition

- there are regular monthly auctions for generics, with the manufacturer with the lowest price wining the auction However, they must be able to supply the whole market for the entire period. This typically translates into $70 \%$ of the total sales during the period (almost $80 \%$ when the crossed prescriptions are excluded) when the washout period and out-of-stock situations are factored in

This should lead to further falls in the prices of generics

- Introduction of the ' $M$ ' and 'W' (Manufacturer and Wholesaler) scheme in the UK in 2005 resulted in increasing transparency in the pricing of generics, as well as discounts and rebates offered by manufacturers to community pharmacists to preferentially dispense their generic

- As a result, there was:

- an average $32.4 \%$ reduction in the prices of generics within the first year of introduction, resulting in a $2 \%$ reduction in overall pharmaceutical expenditure the year following its introduction. Prior to this, some generic manufacturers were offering discounts of up to $80 \%$ or more to community pharmacists to preferentially dispense their particular generic

- reimbursed prices (tariff price) and expenditure/DDD for generic simvastatin $2 \%$ to $3 \%$ of pre-patent loss originator prices

Consequently, there is typically active monitoring of Drug Tariff prices by Pharmaceutical Advisers to enhance potential savings, as well as active monitoring of drug patent expiry dates to identify potential opportunities for switching drugs within a class (ATC Level 4) just before or just after generic availability

Table I. Case history approaches of approaches used by countries to lower the prices of generics and their outcome

ket forces helping to drive prices down through IT systems and physician education to encourage the prescribing of the cheapest branded generic.

Perhaps not surprising, the utilisation of generics versus originators is greater in countries where there is free pricing, with market forces used to drive down prices [39]. As a result, countries such as Slovenia are looking to introduce compulsory generic substitution along with reference pricing for therapeutic drug groups (cluster of drugs for the same therapeutic indication) to further lower prices, including generics, to contain costs. A number of case histories illustrating the influence of the various measures are contained in Table I. The case histories particularly in Lithuania and the Republic Srpska demonstrate that European countries with small populations can introduce multiple reforms including those to obtain low prices for generics [36,42]. As a result, dispel myths that countries with smaller populations have difficulties negotiating with manufacturers and obtaining low prices for drugs [111].

\section{Measures to enhance the utilisation of generics versus originators}

A range of measures have been introduced in France in recent years to enhance the prescribing and dispensing of generics versus originators. These include $[2,6-8,10,15]$ :

\section{- Physicians:}

- authorities publishing and updating the list of generic products available, as well as regularly benchmarking ambulatory care physicians on their generic prescribing rates benchmarked with colleagues and providing feedback;

- introducing Pay for Performance (P4P) measures whereby GPs receive additional payment for increasing the prescribing of generics in a class (ATC Level 4) or group of classes (ATC Level 3). Classes include antibiotics, PPIs, statins, antihypertensive drugs as well as antidepressants.

\section{- Pharmacists:}

- guaranteed the same absolute margin for both generic and originator medicines; 
- instigation of annual substitution targets linked with the national agreement between the pharmacists and the Health Insurance Fund.

\section{- Patients:}

- government promotional campaigns to enhance the acceptance of generics and INN prescribing;

- Health Insurance Funds promoting generics on the back of reimbursement forms sent to patients;

- patients must pay the Health Insurance proportion of the cost of a drug if they refuse substitution $30 \%$ for comfort drugs, $65 \%$ for the majority, and $100 \%$ for essential drugs - although $85 \%$ of the population have supplementary insurance covering the difference) and subsequently can claim this back. However, if patients accept substitution, the pharmacists cover these costs themselves and claim this back afterwards

As discussed, these measures, coupled with a prescriptive pricing policy for generics, led to annual savings estimated at $€ 1 \mathrm{bn}$ in 2007, $€ 0.905$ bn in 2008 and $€ 1.01$ bn in 2009 [15]. The early analysis of the pilot P4P programme (Contrat d'Amélioration des Pratiques Individuelles - CAPI) also indicates a positive influence on physician behaviour; consequently, it has now been extended to all GPs in France [63]. In Portugal, the current target goal is to reduce NHS expenditure in 2012 by over $10 \%$ versus 2011 levels, and by a further $20 \%$ in 2013 , achieved by introducing a range of supply- and demand-side measures. These include for pharmaceuticals:

\section{- Supply-side measures:}

- pricing of generics - the first generic must be lower than $50 \%$ than the prepatent originator price to be reimbursed. By the time the fifth generic is available, its price must be $5 \%$ lower than the latest generic submitted for reimbursement;

- instigation of a reference price system based on the 5 cheapest molecules (ATC Level 5), with patients covering the additional cost themselves for a more expensive molecule;

- removing/reducing some of the current legal/administrative barriers to the entry of generics to hasten their introduction in Portugal.

\section{- Demand-side measures:}

- generic advertising campaigns to all key stakeholder groups including physicians and patients (Figure 1);

- increasing IT support including electronic medical prescribing as well as other measures to enhance the rational use of medicines. These include alerts/pop-ups on the cheapest medicinal products available to treat the condition. They also include IT tools to monitor GP prescribing;

- therapeutic guidelines (electronic and hard copy);

- information given to the patient in the prescription about the amount that could be saved if the doctor would have chosen the cheapest medicine for the condition;

- increasing patient co-payments by reducing NHS contributions of high volume ambulatory care drugs, e.g.: i)ulcer therapies decreased from 69 to $37 \%$; ii) anti-inflammatory therapies decreased from 69 to $37 \%$; iii) anti-depressants decreased from 95 to $37 \%$.

As a result, the generic market in Portugal expanded by $16 \%$ January to October 2011 , with costs decreasing by $12 \%$. This favourably impacted on the total market where both volumes and costs are now decreasing.

Other examples to increase the prescribing and dispensing of generics versus originators, some of which are described in Table I, include:

- Lithuania, where all reimbursed prescriptions should be written by INN name except biological products, unless the physician receives prior approval from the Hospital or Polyclinic Therapeutic Committee [36];

- Sweden, where there is currently compulsory generic substitution apart from a minority of situations $[3,4,7,8,15,19]$;

- United Kingdom, where there is high voluntary INN prescribing encouraged through education and follow-up activities. This current averages over $82 \%$ across all products and up to $99.5 \%$ once drugs lose their patent, e.g. generic simvastatin $[10,15,33,37,38]$.

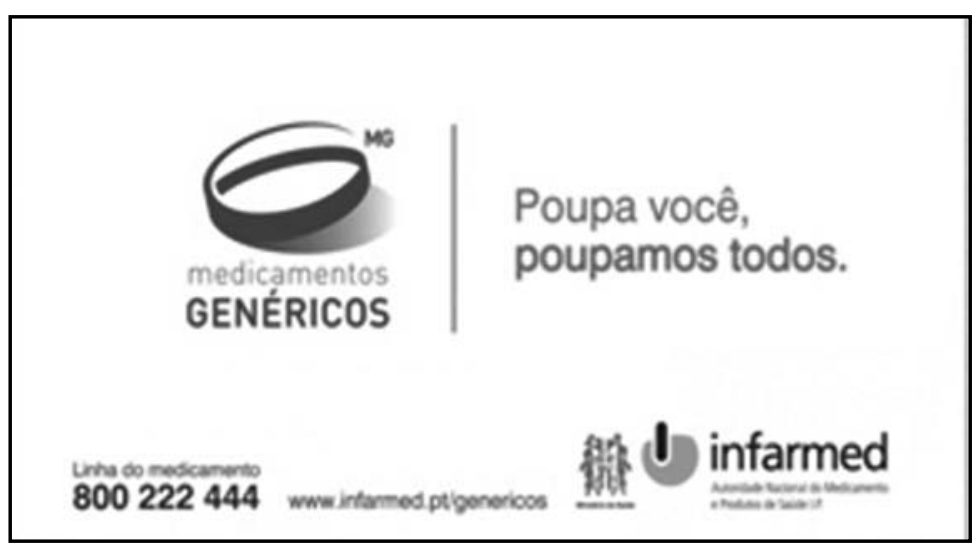

Figure 1. Part of the generics advertising campaign to patients 
Class

PPIs $[6-9,15,38,104]$

Statins $[6-9,38,43,104]$

ACEIs/ARBs $[33,44,119]$

\section{Countries, measures and their influence with increasing prescribing efficiency}

Sweden versus Ireland:

- multiple demand side measures, including education, economics, and engineering, appreciably increased the prescribing of omeprazole in Sweden once generics became available, with stable and low utilisation of esomeprazole as a \% of total PPI utilisation ( $<20 \%$ on a DDD basis)

- this compared with Ireland with more limited demand side measures to combat industry activities, where utilisation of omeprazole decreased and the utilisation of esomeprazole increased following the availability of generic omeprazole, with both approximately 30\% of total PPI utilisation in 2007

- this combined with the measures to lower the prices of generics in Sweden (Table I) resulted in reimbursed expenditure for PPIs decreasing by 49\% in 2007 vs. 2001 despite utilisation increasing by $53 \%$. This compares with a 2.6 fold increase in expenditure in Ireland during the same period versus a 2.4 fold increase in utilisation

- as a result, reimbursed expenditure (Euros/1000 inhabitants/year in Ireland (GMS population greater co-morbidity than the normal population) in 2007 was over 10 fold greater at over $€ 60,000$ versus €5832 for Sweden

Netherlands:

- multiple demand side measures introduced in the Netherlands, coupled with supply side measures to lower generic prices (described in Table 1), led to reimbursed expenditure for the PPIs falling by $58 \%$ in 2010 vs. 2000. This was despite a 3 fold increase in utilisation

Scotland:

- multiple demand side measures, coupled with supply-side measures to lower generic prices (Table I), resulted in expenditure/1000 inhabitants/year for the PPIs in 2010 at GB£5481 (€6301), 56\% below 2001 levels despite a 3 fold increase in utilisation

- it is estimated that PPI expenditure in Scotland would have been GB£159mn per year greater in 2010 - assuming similar overall utilisation coupled with utilisation patterns and their costs kept the same as the pre-patent loss situation

Austria:

- restrictions limiting the prescribing of patented statins (atorvastatin and rosuvastatin), combined with measures to lower the prices of generics and originators (Table I), resulted in a 3\% decrease in total expenditure for the statins in 2007 versus 2001 despite approximately 2.4 fold increase in utilisation Sweden versus Ireland:

- there was a similar situation with the statins, with the utilisation of atorvastatin and rosuvastatin rising appreciably in Ireland following the availability of generic simvastatin, accounting for nearly $80 \%$ of all statin utilisation (DDD basis) in 2007

- as a result, statin expenditure increased 4.9 fold in Ireland between 2001 and 2007 for the GMS population (utilisation increasing 7.3 fold) versus a 39\% reduction in Sweden (compared with a 3.2 fold increase in utilisation)

- again, reimbursed expenditure (Euros/1000 inhabitants/year) in Ireland (GMS population) in 2007 was over 10 fold greater than Sweden at over $€ 60,000$ versus $€ 5192$ for Sweden

Netherlands:

- multiple demand side measures, coupled with supply side measures to lower generic prices (Table I), led to reimbursed expenditure for the statins falling by $14 \%$ in 2010 vs. 2000 despite a 3.8 fold increase in utilisation

Scotland:

- multiple demand side measures, coupled with supply-side measures to lower generic prices (Table I), resulted in expenditure/1000 inhabitants/year for the statins in 2010 at GB£11420/1000 inhabitants (€13113) only 7\% above 2001 levels despite a 6.2 fold increase in utilisation

- expenditure for the statins would have been GB£290mn per year greater in 2010 assuming similar overall utilisation coupled with utilisation patterns and their costs kept the same as the pre-patent loss situation

ACEIs and ARBs in Austria, Croatia and Scotland:

- expenditure (Euros)/1000 inhabitants/year remained relatively stable for the renin-angiotensin inhibitor drugs in Austria, Croatia and Scotland between 2001 and 2007 despite volumes increasing by between $69 \%$ to $159 \%$ during this period through multiple supply-side (see text) and demand side measures

- multiple initiatives were undertaken in Scotland to limit ARB prescribing including education, economics and engineering initiatives

Losartan versus other ARBs in Austria:

- the prescribing restrictions were relaxed for losartan, but not the other ARBs, following the availability of generic losartan

- this appreciably increased the utilisation of losartan versus other single ARBs slowing down the rate of growth in ARB expenditure, with expenditure/DDD for losartan declining by $78 \%$ by the end of August 2011 compared with pre-patent loss prices

Losartan versus other ARBs in NHS Bury:

- the Pharmacy team in NHS Bury instigated multiple measures to increase the prescribing of losartan versus other ARBs with generic losartan at appreciably lower prices than patented ARBs. These included educational activities, financial incentives as well as active switching programmes from other ARBs to losartan

- the programmes led to estimated savings at over eight times the cost of implementation, helping to reach target expenditure goals without compromising care

Table II. Case histories of combined measures amongst European countries and their outcome 


\section{Measures to enhance the utilisation of generics versus patented products in a class or related class}

A plethora of measures and initiatives have been introduced among health authorities and health insurance agencies across Europe to encourage the prescribing of generics versus patented products in a class or related class. These can be collated under the $4 \mathrm{Es}$ - namely Education, Engineering, Economics and Enforcement, and incorporate [4,6-10,15,3338,41-53,63,112]:

- Education: includes programmes influencing the prescribing of generics through dissemination of material as well as monitoring and benchmark activities. Examples include (i) distribution of guidelines, guidance and formularies such as the 'Wise Lit' in Stockholm, Sweden, (ii) academic detailing (iii) monitoring or benchmarking of physician prescribing habits (iv) encouraging.

- Engineering activities: are concerned with organizational or managerial interventions, and include (i) prescribing targets and quality targets such as the $\mathrm{P} 4 \mathrm{P}$ measures in France and the Better Care/ Better Value indictors for high volume disease areas in the UK, (ii) disease management programmes, (iii) agreed generic substitution rates in community pharmacies such as those in France.

- Economics: includes both positive and negative financial interventions. Examples include (i) patients covering the additional cost themselves for a more expensive drug than the current reference priced drug (molecule or class), (ii) financial incentives to physicians for reaching agreed prescribing targets or (iii) financial penalties for continued high cost prescribing.

- Enforcement: refers to regulations by law. Examples have included (i) compulsory generic substitution in Sweden, (ii) mandatory INN prescribing in Lithuania apart from exempt cases, (iii) prescribing restrictions such as those for patented statins in Austria, Finland, Norway and Sweden as well as patented ARBs versus typically generic ACEIs in Austria, Croatia, Lithiania and Sweden.

It has typically been found that multiple interventions are needed to appreciably change physician prescribing behaviour such as increasing the prescribing of generics within a class or related class, and hence prescribing efficiency $\quad[4,6-9,15,33,37,38,50,113,114]$. This is illustrated by the case histories in Table II for the PPIs, statins and the various renin-angiotensin inhibitor system drugs. As discussed earlier, the products in each of these three classes or related classes are seen as essentially similar in all or nearly all patients. Consequently, the goal of health authorities and health insurance companies is to increase the prescribing of generics in each class once available, and restrict the utilisation of existing patented products. However, this is not easy with pharmaceutical companies investing considerable resources to influence the prescribing of particularly patented products, with promotional expenditure as high as US\$53bn in the US alone in 2004 [31,115-117].

The ongoing reforms in Portugal described earlier also comprise multiple supply- and demand-side measures to considerably reduce pharmaceutical expenditure in light of the current financial situation [118] whilst still providing comprehensive health care.

\section{DISCUSSION}

We believe we have shown that health authorities and health insurance companies have successfully introduced a plethora of multiple supply- and demand-side measures and initiatives across Europe to appreciably improve prescribing efficiency. This is irrespective of the size of the population of the country. This includes measures to lower the price of generics as well as increase their utilisation versus originators and patented products in the class or related classes. Typically, multiple measures and initiatives are needed to appreciably change prescribing behaviour given the considerable resources spent by pharmaceutical companies on promotional activities and their known influence [120-125].

Consequently, we believe these many reforms and initiatives are here to stay particularly in Europe given the current economic situation coupled with ageing populations, rising patient expectations and the continued launch of new premium priced drugs. As demonstrated (Table II), the increasing use of generics at lower costs than patented drugs provides considerable opportunities for authorities to conserve resources without compromising care, especially if the quality of generics is maintained through the EMA and country regulatory authorities.

As a result, we believe it is inevitable that there will be increasing use of generics across Europe, especially as more standard drugs lose their patents. The alternative is insufficient funds to cover the costs of increasing drug volumes with ageing populations across Europe and/or difficulties with funding new 
innovative drugs. Neither of these scenarios are in the best interests of key stakeholder groups including patients and physicians as well as innovative pharmaceutical companies. We are already seeing countries learning from each other (Tables I and II). This includes initiatives to obtain low prices for generics through market forces and other measures. Examples include increasing the transparency in the prices of generics such as tendering and regular monitoring of the manufacturing costs as well as any discounts or rebates in the system. In addition, instigating advertising and other campaigns to allay potential patient fears regarding generics, compulsory INN prescribing or compulsory substitution. Examples of countries learning from each other regarding demand-side measures to increase the prescribing of generics versus patented products include prescribing targets linked with financial payments, the use of patient co-payments, financial incentives for physicians to adhere to formularies as well as prescribing restrictions for existing patented products in a class. However, the nature, timing and follow-up of any prescribing restrictions have to be carefully considered and addressed else health authorities and health insurance agencies could be disappointed with the outcome $[9,15,33,46,112]$. The pace of learning is likely to accelerate among European countries as resource pressures continue to grow, and will be the subject of future research.

\section{ACKNOWLEDGEMENTS}

The production of this review article was in part supported by grants from the Karolinska Institutet.

\section{REFERENCES}

1. Godman B, Bucsics A, Burkhardt T, et al. Insight into recent reforms and initiatives in Austria; implications for key stakeholders. Expert Rev Pharmacoeconomcis Outcomes Research 2008; 8: 357-71; http://dx.doi. org/10.1586/14737167.8.4.357

2. Sermet C, Andrieu V, Godman B, et al. Ongoing pharmaceutical reforms in France; implications for key stakeholder groups. Applied Health Economics and Health Policy 2010; 8: 7-24

3. Wettermark B, Godman B, Andersen K, et al. Recent national and regional drug reforms in Sweden - implications for pharmaceutical companies in Europe. Pharmacoeconomics 2008; 26: 537-50; http://dx.doi.org/10.2165/00019053200826070-00001

4. Godman B, Wettermark B, Hoffman M, et al. Multifaceted national and regional drug reforms and initiatives in ambulatory care in Sweden; global relevance. Expert Rev Pharmacoeconomcis Outcomes Research 2009; 9: 6583; http://dx.doi.org/10.1586/14737167.9.1.65

5. Coma A, Zara C, Godman B, et al. Policies to enhance the efficiency of prescribing in the Spanish Catalan Region: impact and future direction. Exp Review of Pharmacoeconomics and Outcomes Research 2009; 9: 569-81; http:// dx.doi.org/10.1586/erp.09.58

6. Godman B, Shrank W, Wettermark B, et al. Use of generics - a critical cost containment measure for all healthcare professionals in Europe? Pharmaceuticals 2010; 3:2470-94 doi 10.3390/ph/3082470

7. Godman B, Shrank W, Andersen M, et al. Comparing policies to enhance prescribing efficiency in Europe through increasing generic utilisation: changes seen and global implications. Expert Rev. Pharmacoeconomics Outcomes Res 2010; 10: 707-22; http://dx.doi.org/10.1586/erp.10.72

8. Godman B, Shrank W, Andersen M, et al. Policies to enhance prescribing efficiency in Europe: findings and future implications. Frontiers Pharmacol 2011; 1: 1-16 doi: 10.3389/fphar.2010.00141; http://dx.doi.org/10.3389/ fphar.2010.00141

9. Godman B, Malmstrom RE, Bennie M, et al. Prescribing restrictions - a necessary strategy among some European countries to enhance future prescribing efficiency? Reviews in Health Care 2012; 3: 5-16

10. Godman B, Wettermark B, Bishop I, et al. European payer initiatives to reduce prescribing costs through use of generics. GaBI 2012; 1: 22-7

11. Vogler S. The impact of pharmaceutical pricing and reimbursement policies on generics uptake: implementation of policy options on generics in 29 European countries - an overview. GaBI 2012; 1: 93-100

12. OECD. Pharmaceutical expenditure. In: OECD, Health at a Glance 2011: OECD Indicators. OECD Publishing. doi: 10.1787/health glance-2011-63-en Available via URL: http://www.oecd-ilibrary.org/docserver/download/ fulltext/8111101ec063.pdf?expires=1343281688\&id=id\&accname=guest\&checksum=4D4F46B30255998AA8 1601571E18EE8F [Accessed 20 July 2012); http://dx.doi.org/10.1787/health_glance-2011-63-en 
13. Dylst P, Vulto A, Simoens S. Tendering for outpatient prescription pharmaceuticals: what can be learnt from current practices in Europe. Health Policy 2011; 102:146-52; http://dx.doi.org/10.1016/j.healthpol.2011.03.004

14. Cameron A, Ewan M, Ross-Degnan D, et al. Medicine prices, availability and affordability in 36 developing and middle-income countries: a secondary analysis. Lancet 2009; 373: 240-49; http://dx.doi.org/10.1016/S01406736(08)61762-6

15. Godman B, Abuelkhair M, Vitry A, et al. Payers endorse generics to enhance prescribing efficiency; impact and future implications, a case history approach. GaBI 2012;1:21-35

16. OECD (2011). Health at a Glance 2011: OECD Indicators. OECD Publishing. http://www.oecd-ilibrary.org/ docserver/download/fulltext/8111101 ec003.pdf?expires $=1343282225 \& \mathrm{id}=\mathrm{id} \&$ accname= guest\&checksum=839 2DB2BAF7C83E91707713E9726AF9D (Accessed 20 July 2012)

17. Quintal C, Mendes P. Underuse of generic medicines in Portugal: an empirical study on the perceptions and attitudes of patients and pharmacists. Health Policy 2012; 104: 61-8; http://dx.doi.org/10.1016/j.healthpol.2011.10.001

18. Garattini S, Bertele V, Godman B, et al. Enhancing the rational use of new medicines across European healthcare systems - A Position Paper. Eur J Clinical Pharmacology 2008; 64: 1137-8; http://dx.doi.org/10.1007/s00228008-0537-z

19. Cheema PK, Gavura S, Migus M, et al. International variability in the reimbursement of cancer drugs by publically funded drug programs. Curr Oncol 2012; 19: 165-176; http://dx.doi.org/10.3747/co.19.946

20. Jemal A, Center MM, DeSantis C, et al. Global patterns of cancer incidence and mortality rates and trends. Cancer Epidemiol Biomarkers Prev 2010; 19: 1893-907; http://dx.doi.org/10.1158/1055-9965.EPI-10-0437

21. Savage P. Development and economic trends in cancer therapeutic drugs in the U.K. from 1955 to 2009. J Oncol Pharm Pract 2012; 18: 52-6; http://dx.doi.org/10.1177/1078155210389218

22. Nagle PC, Nicita CA, Gerdes LA, Schmeichel CJ. Characteristics of and trends in the late-stage biopharmaceutical pipeline. Am J Manag Care 2008;14: 226-9

23. Sullivan R, Peppercorn P, Sikora K, et al. Delivering affordable cancer care in high-income countries. Lancet Oncology 2011; 12: 933-80; http://dx.doi.org/10.1016/S1470-2045(11)70141-3

24. Dranitsaris D, Truter I, Lubbe M, et al. Advancers in cancer therapeutics and patient access to new drugs. Pharmacoeconomics 2011; 29: 213-24; http://dx.doi.org/10.2165/11584210-000000000-00000

25. Hillner B, Smith T. Efficacy does not necessarily translate to cost effectiveness: a case study in the challenges associated with 21st-century cancer drug pricing. J Clin Oncol 2009; 27: 2111-3; http://dx.doi.org/10.1200/ JCO.2008.21.0534

26. National Cancer Institute. Surveillance Epidemiology and End Results (SEER). Washington, DC: National Cancer Institute, 2010 [online]. Available from URL: http://seer.cancer.gov/ [Accessed March 2012]

27. Sobrero A, Bruzzi P. Incremental advance or seismic shift? The need to raise the bar of efficacy for drug approval. Jn Clinical Oncology 2009; 27: 5868-73; http://dx.doi.org/10.1200/JCO.2009.22.4162

28. Yukhananov A. Reuters available via URL: http://www.reuters.com/article/2011/08/26/fda-pfizer-idUSN1E77P1UG20110826 [Accessed 2 April 2012]

29. UK Medicines Information. http://www.ukmi.nhs.uk/applications/ndo/record_view_open.asp?newDrugID=5009 [Accessed 2 April 2012]

30. MediReviews. http://www.medireviews.com/zelboraf-vemurafenib.html [Accessed 2 April 2012]

31. Godman B, Haycox A, Schwabe U, et al. Having your cake and eating it: Office of Fair Trading proposal for funding new drugs to benefit patients and innovative companies. Pharmacoeconomics 2008; 26:91-8; http://dx.doi. org/10.2165/00019053-200826020-00001

32. Voncina L, Strizrep T. Croatia: 2009/2010 pharmaceutical pricing and reimbursement forum. Eurohealth 2011; 16: $20-2$

33. Vončina L, Strizrep T, Godman B, et al. Influence of demand side measures to enhance renin-angiotensin prescribing efficiency in Europe; implications for the future. Expert Rev Pharmacoeconomics and Outcomes Res 2011; 11: 469-79; http://dx.doi.org/10.1586/erp.11.42

34. Brkičic L, Godman B, Vončina L, et al. Initiatives to improve prescribing efficiency for drugs to treat Parkinson's Disease in Croatia; influence and future directions. Expert Rev Pharmacoeconomics and Outcomes Research 2012; 12:373-84; http://dx.doi.org/10.1586/erp.12.24 
35. Garuoliene K, Alonderis T, Marcinkevičius M. Pharmaceutical policy and the effects of the economic crisis: Lithuania. EuroHealth 2011; 17: 1-4

36. Garuoliene K, Godman B, Gulbinovič J, et al. European countries with small populations can obtain low prices for drugs: Lithuania as a case history. Expert Rev Pharmacoeconomics Outcomes Res 2011; 11: 343-9; http:// dx.doi.org/10.1586/erp.11.24

37. McGinn D, Godman B, Lonsdale J, et al. Initiatives to enhance the quality and efficiency of statin and PPI prescribing in the UK; impact and implications. Expert Rev Pharmacoeconomics and Outcomes Res 2010; 10: 73-85; http://dx.doi.org/10.1586/erp.09.73

38. Bennie M, Godman B, Bishop I, et al. Multiple initiatives continue to enhance the prescribing efficiency for the proton pump inhibitors and statins in Scotland. Expert Review Pharmacoeconomics and Outcomes Research 2012; 12: 125-130; http://dx.doi.org/10.1586/erp.11.98

39. Dylst P, Vulton A, Simoens S. The impact of reference pricing systems in Europe: a literature reviews and case studies. Expert Rev Pharmacoeconomics and Outcomes Research 2011; 11: 729-37; http://dx.doi.org/10.1586/ erp. 11.70

40. Simoens S. A review of generic medicine pricing in Europe. GaBI 2012; 1: 8-12

41. Abuelkhair M, Abdu S, Godman B, et al. Imperative to consider multiple initiatives to maximise prescribing efficiency from generic availability: case history from Abu Dhabi. Expert Review Pharmacoeconomics and Outcomes Research 2012; 12: 115-24; http://dx.doi.org/10.1586/erp.11.90

42. Markovic-Pekovic V, Ranko Škrbić R, Godman B, et al. Ongoing initiatives in the Republic of Srpska to enhance prescribing efficiency; influence and future direction. Expert Review of Pharmacoeconomics and Outcomes Research 2012; 12: 661-71

43. Godman B, Burkhardt T, Bucsics A, et al. Impact of recent reforms in Austria on utilisation and expenditure of PPIs and lipid lowering drugs; implications for the future. Expert Rev Pharmacoeconomics Outcomes Research 2009; 9:475-84; http://dx.doi.org/10.1586/erp.09.43

44. Godman B, Buscics A, Burkhardt T, et al. Initiatives to enhance renin-angiotensin prescribing efficiency in Austria; impact and implications for other countries. Expert Rev Pharmacoeconomics and Outcomes Research 2010; 10: 199-207; http://dx.doi.org/10.1586/erp.10.6

45. Sakshaug S, Furu K, Karlstad O, et al. Switching statins in Norway after new reimbursement policy - a nationwide prescription study. Br J Clin Pharmacol 2007; 64: 476-81; http://dx.doi.org/10.1111/j.1365-2125.2007.02907.x

46. Godman B, Sakshaug S, Berg C, et al. Combination of prescribing restrictions and policies to engineer low prices to reduce reimbursement costs. Expert Rev Pharmacoeconomics Outcomes Res 2011; 11: 121-9; http://dx.doi. org/10.1586/erp.10.87

47. Martikainen J, Saastamoinen L, Korhonen M, et al. Impact of restricted reimbursement on the use of statins in Finland -A register-based study. Medical Care 2010; 48: 761-6; http://dx.doi.org/10.1097/MLR.0b013e3181e41bcb

48. Wettermark B, Godman B, Neovius M, et al. Initial effects of a reimbursement restriction to improve the costeffectiveness of antihypertensive treatment. Health Policy 2010; 94: 221-29; http://dx.doi.org/10.1016/j.healthpol.2009.09.014

49. Gustafsson LL, Wettermark B, Godman B, et al. The "Wise List"- A comprehensive concept to select, communicate and achieve adherence to recommendations of essential drugs in ambulatory care in Stockholm. Basic \& Clinical Pharmacology \& Toxicology 2011; 108: 224-33

50. Wettermark B, Godman B, Jacobsson B, et al. Soft regulations in pharmaceutical policymaking - an overview of current approaches and their consequences. Appl Health Econ Health Policy 2009; 7: 137-47

51. Wettermark B, Pehrsson A, Juhasz-Haverinen M, et al. Financial incentives linked to self-assessment of prescribing patterns - a new approach for quality improvement of drug prescribing in primary care. Quality in Primary Care 2009; 17: 179-89

52. Baumgärtel C, Godman B, Malmström R, et al. What lessons can be learned from the launch of generic clopidogrel? GaBI 2012; 1: 10-20

53. Godman B, Schwabe U, Selke G, et al. Update of recent reforms in Germany to enhance the quality and efficiency of prescribing of proton pump inhibitors and lipid lowering drugs. Pharmacoeconomics 2009; 27: 435-8; http:// dx.doi.org/10.2165/00019053-200927050-00010

54. Araszkiewicz AA, Szabert K, Godman B, et al. Generic olanzapine: health authority opportunity or nightmare? Expert Rev Pharmacoeconomics Outcomes Res 2008; 8:549-55; http://dx.doi.org/10.1586/14737167.8.6.549 
55. Taylor L. Australian govt blocks subsidies for new drugs. March 2011. Available via URL: http://www.pharmatimes.com/Article/11-03-15/Australian_govt_blocks_subsidies_for_new_drugs.aspx [Accessed 2 April 2012]

56. Barrett A, Roques T, Small M, et al. How much will Herceptin really cost? BMJ 2006; 33: 1118-20; http://dx.doi. org/10.1136/bmj.39008.624051.BE

57. Hoebert J, Mantel-Teeuwisse, van Dijk L et al. Do rheumatoid arthritis patients have equal access to treatment with new medicines? Tumour necrosis factor-alpha inhibitors use in four European countries. Health Policy 2012; 104: 76-83; http://dx.doi.org/10.1016/j.healthpol.2011.10.011

58. Wettermark B, Persson M, Wilking N, et al. Forecasting drug utilization and expenditure in a metropolitan health region. BMC Health Services Research 2010; 10: 128; http://dx.doi.org/10.1186/1472-6963-10-128

59. Adamski J, Godman B, Ofierska-Sujkowska G, et al. Review of risk sharing schemes for pharmaceuticals: considerations, critical evaluation and recommendations for European payers. BMC Health Services Research 2010; http://dx.doi.org/10.1186/1472-6963-10-153

60. Paterson K, McIver L, Booth C. Schnellbewertung neuer Arzneimittel - bur ein Modell für Scotland. GGW2010; 10: 16-23 (The Scottish Medicines Consortium - Rapid Health Technology Assessment of Medicines)

61. Wettermark B, Godman B, Eriksson C, et al. Einführung neuer Arzneimittel in europäische Gesundheitssysteme. $G G W 2010$; 10: 24-34 (Introduction of new medicines into European healthcare systems)

62. Joppi R, Demattè L, Menti AM, et al. The Italian Horizon Scanning Project. Eur J Clin Pharmacol 2009; 65: 775-81; http://dx.doi.org/10.1007/s00228-009-0666-z

63. Godman B, Paterson K, Malmstrom R et al. Improving the managed entry of new medicines: sharing experiences across Europe. Expert Review Pharmacoeconomics and Outcomes Res 2012; 12: 439-41

64. Jarolawski S, Toumi M. Market access agreements for pharmaceuticals in Europe: diversity of approaches and underlying concents. BMC Health Services Research 2011; 11:259 (http://www.biomedcentral.com/14726963//11/259); http://dx.doi.org/10.1186/1472-6963-11-259

65. Nachtnebel A, Geiger-Gritsch S, Hintringer K, et al. Scanning the horizon - Development and implementation of an early awareness system for anticancer drugs in Austria. Health Policy 2012; 104:1-11; http://dx.doi.org/10.1016/j. healthpol.2011.11.003

66. Dylst P, Vulto A, Simoens S, et al. Where a cheap medicine is not the same as a generic medicine: the Belgian case. JPHSR 2011; 2: 185-99

67. Frank R. The ongoing regulation of generic drugs. $N$ Eng J Med 2007; 357: 1993-6; http://dx.doi.org/10.1056/ NEJMp078193

68. Jack, A. Balancing Big Pharma’s books. BMJ 2008; 336: 418-9; http://dx.doi.org/10.1136/bmj.39491.469005.94

69. EATG. 2009 world pharma sales forecast to top $\$ 820$ billion. Available via URL: http://www.eatg.org/eatg/GlobalHIV-News/Pharma-Industry/2009-world-pharma-sales-forecast-to-top-820-billion [Accessed 11 June 2012]

70. World Health Organisation. The World health report 2010: health systems financing: the path to universal coverage. Geneva 2010. Available via URL: http://www.who.int/whr/2010/whr10_en.pdf [Accessed 6 June 2010]

71. European Commission [homepage on the Internet]. Pharmaceutical Forum: First Progress Report, 29 September 2006. 2007 [cited $2011 \mathrm{Dec}$ 11]. Available from: http://ec.europa.eu/health/ph_overview/other_policies/pharmaceutical/pharma_forum_progres_report092006_en.pdf [Accessed 12 June 2012]

72. Commission Communication of 10 December 2008 COM (2008) 666: final. Safe, innovative and accessible medicines: a renewed vision for the pharmaceutical sector. DG Competition of the European Commission. Pharmaceutical Sector Inquiry. Brussels, July 2009. Available from: eur-lex.europa.eu/LexUriServ/LexUriServ. do?uri=COM:2008:0666:FIN:en:PDF [Accessed 12 July 2012]

73. Kalpan W, Ritz L, Vitello M, et al. Policies to promote use of generic medicines in low and middle income countries: A review of published literature, 2000 to 2010. Health Policy 2012; 106: 211-24; http://dx.doi.org/10.1016/j. healthpol.2012.04.015

74. Downing NS, Ross JS, Jackevicius CA, et al. Avoidance of Generic Competition by Abbott Laboratories' Fenofibrate Franchise. Arch Intern Med 2012 Apr 9. [Epub ahead of print]

75. Cameron A, Laing R. Cost savings of switching private sector consumption from originator brand medicines to generic equivalents. World Health Organization [homepage on the Internet]. Available from: http://www.who.int/ healthsystems/topics/financing/healthreport/35MedicineCostSavings.pdf [Accessed 12 July 2012]

76. World Health Organisation (WHO). Guidelines for ATC classification and DDD assignment 2009. Oslo: WHO 
Collaborating Centre for Drug Statistics Methodology. www.whocc.no [Accessed 5 March 2012]

77. Puig-Junoy. Impact of European Pharmaceutical Price Regulation on Generic Competition. Pharmaeconomics 2010; 8: 649-63

78. Vogler S, Zimmermann N, Leopold C, et al. Pharmaceutical policies in European countries in response to the global financial crisis. Southern Med Review 2011; 4: 22-32; http://dx.doi.org/10.5655/smr.v4i2.1004

79. Ferner R, Lenney W, Marriott J. Controversy over generic substitution. BMJ 2010; 340: c2548; http://dx.doi. org/10.1136/bmj.c2548

80. Duerden MG, Hughes DA. Generic and therapeutic substitutions in the UK: are they a good thing? Br J Clin Pharmacol 2010; 70: 335-41; http://dx.doi.org/10.1111/j.1365-2125.2010.03718.x

81. Baumgärtel C. Myths, questions, facts about generic drugs in the EU. GaBI 2012; 1: 34-8

82. Baumgärtel C. Generic clopidogrel-the medicines agency’s perspective. GaBI 2012; 1: 89-91

83. Sanofi Aventis. Sanofi-aventis Confirms Quality and Supply of Plavix ${ }^{\circledR}$, Iscover ${ }^{\circledR}$ and Clopidogrel Winthrop ${ }^{\circledR}$ Paris. March 2010. Available via URL: http://en.sanofi-aventis.com/binaries/20100326_Clopidogrel_en_tcm2827815.pdf (Accessed 20 June 2012)

84. Kesselheim A, Stedman M, Bubrick E, et al. Seizure outcomes following the use of generic versus brandname antiepileptic drugs. A systematic review and meta-analysis. Drugs 2010; 70: 605-621; http://dx.doi. org/10.2165/10898530-000000000-00000

85. Kesselheim A, Misoni A, Lee J, et al. Clinical equivalence of generic and brand-name drugs used in cardiovascular disease - a systematic review and meta-analysis. JAMA 2008; 300: 2514-26; http://dx.doi.org/10.1001/ jama.2008.758

86. Maliepaard M, Banishki N, Gispen-de Wied CC, et al. Interchangeability of generic anti-epileptic drugs: a quantitative analysis of topiramate and gabapentin. Eur J Clin Pharmacol 2011; 67: 1007-16; http://dx.doi.org/10.1007/ s00228-011-1041-4

87. Boh M, Opolski G, Poredos P, et al. Therapeutic equivalence of the generic and the reference atorvastatin in patients with increased coronary risk. Int Angiol 2011; 30: 366-74

88. Pedersen TR, Faergeman O, Kastelein JJ, et al. High-dose atorvastatin vs usual-dose simvastatin for secondary prevention after myocardial infarction: the IDEAL study: a randomized controlled trial. JAMA 2005; 294:243745; http://dx.doi.org/10.1001/jama.294.19.2437

89. Weng TC, Kao Yang YH, Lin SJ, et al. A systematic review and meta-analysis on the therapeutic equivalnce of statins. J Clinical Pharmacy Therapeutics 2010; 35: 139-51; http://dx.doi.org/10.1111/j.1365-2710.2009.01085.x

90. Norman C, Zarrinkoub R, Hasselström J, et al. Potential savings without compromising the quality of care. Int $J$ Clin Pract 2009: 63: 1320-6; http://dx.doi.org/10.1111/j.1742-1241.2009.02129.x

91. Usher-Smith J, Ramsbottom T, Pearmain H, et al. Evaluation of the clinical outcomes of switching patients from atorvastatin to simvastatin and losartan to candesartan in a primary care setting: 2 years on. Int J Clin Pract 2008; 62: 480-4; http://dx.doi.org/10.1111/j.1742-1241.2007.01690.x

92. Roland M. Linking Physicians' Pay to the Quality of Care - A Major Experiment in the United Kingdom. $N$ Eng J Med 2004; 351:1448-54; http://dx.doi.org/10.1056/NEJMhpr041294

93. Doran T, Fullwood C, Gravelle Het al. Pay-for-performance programs in family practices in the United Kingdom. N Eng J Med 2006; 355: 375-84; http://dx.doi.org/10.1056/NEJMsa055505

94. Fletcher A, Palmer A, Bulpitt C. Coughing with angiotensin converting enzyme inhibitors; how much of a problem? J Hypertens 1994; 12: S43-S47

95. Frisk P, Mellgren TO, Hedberg N, et al. Utilisation of angiotensin blockers in Sweden combining survey and register data to study adherence to prescribing guidelines. Eur Jn Clin Pharmacol 2008; 64: 1223-29

96. Moon J, Flett A, Godman B, et al. Getting better value from the NHS drug budget. BMJ 2011; 342: 30-2

97. Heran BS, Wong MM, Heran IK, et al. Blood pressure lowering efficacy of angiotensin receptor blockers for primary hypertension. Cochrane Database Syst Rev 2008; (4): CD003822

98. Svanström H, Pasternak B, Hviid A. Association of treatment with losartan vs. candersartan and mortality among patients with heart failure. JAMA 2012; 307: 1506-12; http://dx.doi.org/10.1001/jama.2012.452

99. Krum H. Optimising management of chronic heart failure. Lancet 2009; 374: 1808-9; http://dx.doi.org/10.1016/ S0140-6736(09)61992-9 
100. Konstam MA, Neaton JD, Dickstein K, et al. Effects of high-dose versus low-dose losartan on clinical outcomes in patients with heart failure (HEAAL study): a randomised, double-blind trial. Lancet 2009; 374:1840-8; http:// dx.doi.org/10.1016/S0140-6736(09)61913-9

101. Godman B, Wettermark B, Bennie M, et al. Enhancing prescribing efficiency through increased utilisation of generics at low prices. (E)Hospital 2011; 13: 28-31

102. Kanavos P. Do generics offer significant savings to the UK National Health Service? Current Medical Research and Opinion 2007; 23: 105-116; http://dx.doi.org/10.1185/030079907X159506

103. Simoens S. International comparison of generic medicine prices. Current medical research and Opinion 2007; 23: 2647-54; http://dx.doi.org/10.1185/030079907X233395

104. van Woerkom M, Piepenbrink JF, Godman B, et al. Ongoing measures to enhance the efficiency of prescribing of PPIs and statins in the Netherlands; influence and future implications. Journal of Comparative Effectiveness Research 2012; 1: 527-38

105. Boonen LH, van der Geest SA, Schut FT, et al. Pharmaceutical policy in the Netherlands: from price regulation towards managed competition. Adv Health Econ Health Serv Res 2010; 22: 53-76; http://dx.doi.org/10.1108/ $\mathrm{S} 0731-2199(2010) 0000022006$

106. Schut F, Van De Ven W. Effects of purchaser competition in the Dutch health system: is the glass half full or half empty? Health Economics, Policy and Law 2011; 6: 109-23; http://dx.doi.org/10.1017/S1744133110000381

107. Policies and Legislation. GaBI online. Available via URL: http://www.gabionline.net/Country-Focus/The-Netherlands/Policies-and-Legislation [Accessed 30 August 2012]

108. The preference policy for generics in the Netherlands- preferred by whom. Focus Reports 10 Dec 2010. Available via URL: http://www.pharma.focusreports.net/index.php\#state=NewsDetail\&id=3659 [Accessed 30 August 2012]

109. Andersson K, Sonesson C, Petzold M, et al. What are the obstacles to generic substitution? An assessment of the behaviour of prescribers, patients and pharmacies during the first year of generic substitution in Sweden. Pharmacoepidemiol Drug Saf 2005; 14: 341-8; http://dx.doi.org/10.1002/pds.1055

110. Glenngård AH, Hjalte F, Svensson M, et al. Health Systems in Transition: Sweden. Copenhagen, WHO Regional Office for Europe on behalf of the European Observatory on Health Systems and Policies, 2005

111. McKee M, Stuckler D, Martin-Moren J. Protecting health in hard times. BMJ 2010; 341: 681-2; http://dx.doi. org/10.1136/bmj.c5308

112. Pettersson B, Hoffmann M, Per Wändell P, et al. Utilization and costs of lipid modifying therapies following health technology assessment for the new reimbursement scheme in Sweden. Health Policy 2012; 104: 84-91; http:// dx.doi.org/10.1016/j.healthpol.2011.10.010

113. Bero LA, Grilli R, Grimshaw JM, et al. Closing the gap between research and practice: an overview of systematic reviews of interventions to promote the implementation of research findings. BMJ 1998; 317: 465-8; http://dx.doi. org/10.1136/bmj.317.7156.465

114. Barton S. Using clinical evidence. BMJ 2001; 322: 503-4; http://dx.doi.org/10.1136/bmj.322.7285.503

115. Civaner M. Sales strategies of pharmaceutical companies in a 'pharmerging' country: the problems will not improve if gaps remain. Health Policy 2012; 106: 225-32; http://dx.doi.org/10.1016/j.healthpol.2012.05.006

116. Kaiser Foundation. Trends in promotional sepnding for prescription drugs, 1996-2007. Available via URL: http:// facts.kff.org/chart.aspx?ch=225 [Accessed 30 July 2012]

117. Lexchin J, Clare Kohler J. The danger of imperfect regulation: OxyContin use in the United States and Canada. International Journal of Risk \& Safety in Medicine 2011; 23: 233-40

118. Broos P. Health policy reforms in tough times: the case of Portugal. Health Policy 2012; 106:17-22; http://dx.doi. org/10.1016/j.healthpol.2012.04.008

119. Buscics A, Godman B, Burkhardt T, et al. Influence of lifting prescribing restrictions for losartan on subsequent sartan utilisation patterns in Austria; implications for other countries. Expert Review of Pharmacoeconomics and Outcomes Research [In Press]

120. Kyle GJ, Nissen LM, Tett SE. Pharmaceutical company influences on medication prescribing and their potential impact on quality use of medicines. J Clin Pharm Ther 2008; 33: 553-9; http://dx.doi.org/10.1111/j.13652710.2008.00948.x

121. Fischer MA, Keough ME, Baril JL, et al. Prescribers and pharmaceutical representatives: why are we still meeting? J Gen Intern Med 2009; 24: 795-801; http://dx.doi.org/10.1007/s11606-009-0989-6 
122. Greving JP, Denig P, van der Veen WJ, et al. Determinants for the adoption of angiotensin II receptor blockers by general practitioners. Soc Sci Med 2006; 63: 2890-8; http://dx.doi.org/10.1016/j.socscimed.2006.07.019

123. Prosser H, Alomnd S, Walley T. Influence on GPs' decision to prescribe new drugs - the importance of who says what. Family Practice 2003; 20: 61-8; http://dx.doi.org/10.1093/fampra/20.1.61

124. Jones M, Greenfield S, Bradley C. Prescribing of new drugs: qualitative study of influences on consultants and general practitioners. BMJ 2001; 323: 378-81; http://dx.doi.org/10.1136/bmj.323.7309.378

125. Tobin L, de Almedia Neto AC, Wutzke S, et al. Influences on the prescribing of new drugs. Aust Fam Physician 2008; 37: 78-80 